\title{
Dysregulation of FOXG1 by ring chromosome 14
}

\author{
Daniela Alosi ${ }^{1 *}$, Laura Line Klitten ${ }^{1,2}$, Mads Bak' ${ }^{1}$, Helle Hjalgrim²,3, Rikke Steensbjerre Møller ${ }^{2,3}$ and Niels Tommerup ${ }^{1}$
}

\begin{abstract}
In this study we performed molecular characterization of a patient with an extra ring chromosome derived from chromosome 14, with severe intellectual disability, epilepsy, cerebral paresis, tetraplegia, osteoporosis and severe thoraco-lumbal scoliosis. Array CGH analysis did not show any genomic imbalance but conventional karyotyping and FISH analysis revealed the presence of an interstitial 14q12q24.3 deletion and an extra ring chromosome derived from the deleted material. The deletion and ring chromosome breakpoints were identified at base-pair level by mate-pair and Sanger sequencing. Both breakpoints disrupted putative long non-coding RNA genes (TCONS00022561;RP11-148E17.1) of unknown function. However, the proximal breakpoint was 225 kb downstream of the forkhead box G1 gene (FOXG1), within the known regulatory landscape of FOXG1. The patient represents the first case of a r(14) arising from an interstitial excision where the phenotype is compatible with dysregulation of FOXG1. In turn, the phenotypic overlap between the present case, the FOXG1 syndrome and the r(14) syndrome supports that dysregulation of FOXG1 may contribute to the classical r(14)-syndrome, likely mediated by dynamic mosaicism.
\end{abstract}

Keywords: Ring chromosome 14, 14q12, Epilepsy, FOXG1, Intellectual disability, Dynamic mosaicism

\section{Background}

Ring chromosome $14(\mathrm{r}(14))$ syndrome is a rare cytogenetic condition leading to a complex array of phenotypic alterations mainly characterized by growth retardation, intellectual disability, distinct facial dysmorphism with broad and flat nasal bridge, prominent forehead, broad philtrum and thin upper lip, short stature, microcephaly, scoliosis and ocular abnormalities such as abnormal retinal pigmentation, retinitis pigmentosa, strabismus, glaucoma and abnormal macula. Furthermore the patients suffer from intellectual disability, with aggressive and hyperactive behavior in some cases. Another highly characteristic finding is drug resistant epilepsy with onset during the first year of life [1-7]. Less than 80 cases have been reported in the literature and the molecular mechanisms leading to this phenotype remain to be elucidated.

Forkhead Box G1 gene (FOXG1) encodes a brainexpressed winged-helix transcriptional repressor, shown to be critical for forebrain development. The gene is located on 14q12 and disruption and/or dysregulation of FOXG1 has been shown to cause the FOXG1-syndrome

\footnotetext{
* Correspondence: alosi@sund.ku.dk

'Department of Cellular and Molecular Medicine, Wilhelm Johannsen Centre for Functional Genome Research, University of Copenhagen, Copenhagen, Denmark

Full list of author information is available at the end of the article
}

[8-14], characterized by severe postnatal microcephaly, early-onset epilepsy, brain abnormalities, severe intellectual disability, with absent or minimal language development, deficient social interactions including poor eye contact denoting a syndromic form of autism, dyskinesia with mixed features of athetosis, chorea and dystonia, epilepsy, poor sleep patterns, irritability, excessive episodes of crying and frequent gastro-oesophageal reflux $[8,9,12-15]$. In contrast to the $r(14)$-syndrome, only a mild distinct facial dysmorphism is observed in the FOXG1-syndrome, and only in patients with deletions [12-16]. Here we report a patient with a deleted chromosome 14 and an extra ring chromosome, where mate pair sequencing revealed a balanced excision of a $50 \mathrm{Mb}$ segment of chromosome 14, with truncation of the FOXG1 regulatory landscape, and a phenotype overlapping with the $\mathrm{r}(14)$-syndrome.

\section{Case presentation}

Our patient (deceased in 2009) was an 18 year-old female patient. She was born from healthy unrelated parents after an uncomplicated pregnancy. She presented with delayed psychomotor development from approximately 2 months of age. Subsequently, severe intellectual disability (ID), cerebral paresis, tetraplegia, osteoporosis, severe thoraco-lumbal scoliosis, loss of vision, no language 
and no eye-contact became clinically apparent. The patient was permanently wheelchair bound. In addition, the patient was suffering from treatment-resistant epilepsy with generalized tonic-clonic seizures (GTCS), often in series, with onset at about 1 year-of-age. Despite medical treatment the patient experienced weekly seizures throughout her life. Dysmorphic facial features were not mentioned in the medical record. Computed tomography, performed at 1 year of age, showed microcephaly. Brain magnetic resonance imaging performed at 3 years of age showed a central and cortical atrophy and hypoplasia of corpus callosum.

\section{Methods and results}

\section{Karyotypyng and CGH}

Conventional cytogenetic analysis performed during childhood showed a deletion of 14q24.2 together with a marker chromosome. The karyotype was reported as: 47,XX,del (14)(q24.2) + mar. Genome-Wide Human SNP array 6.0
(Affymetrix, Santa Clara, CA, USA) analyzed with Genotyping Console version 3.0 (GTC 3.0, Affymetrix, Santa Clara, CA, USA) did not show any unbalanced features in the genome (data not shown). Since no copy number variations were detected by array screening, the ring chromosome most likely consisted of the material missing from the derivative chromosome 14, with the reported karyotype: 47,XX, del(14)(q21q32.1) + r(14)? (Figure 1).

\section{Mate-pair and sanger sequencing}

In order to fine map the chromosomal breakpoints, we performed Next Generation mate-pair sequencing (MPS) (Illumina Genome Analyzer II (GA-II), Illumina Inc., San Diego, CA, USA) on peripheral blood DNA. MPS libraries of patient genomic DNA were prepared according to the manufacturer's instructions (Mate Pair Library v2, Illumina) and sequenced $2 \times 36$ bases on a Genome Analyzer IIx (Illumina). A total of 31,960,052 out of $46,169,874$ read-pairs could be aligned to the
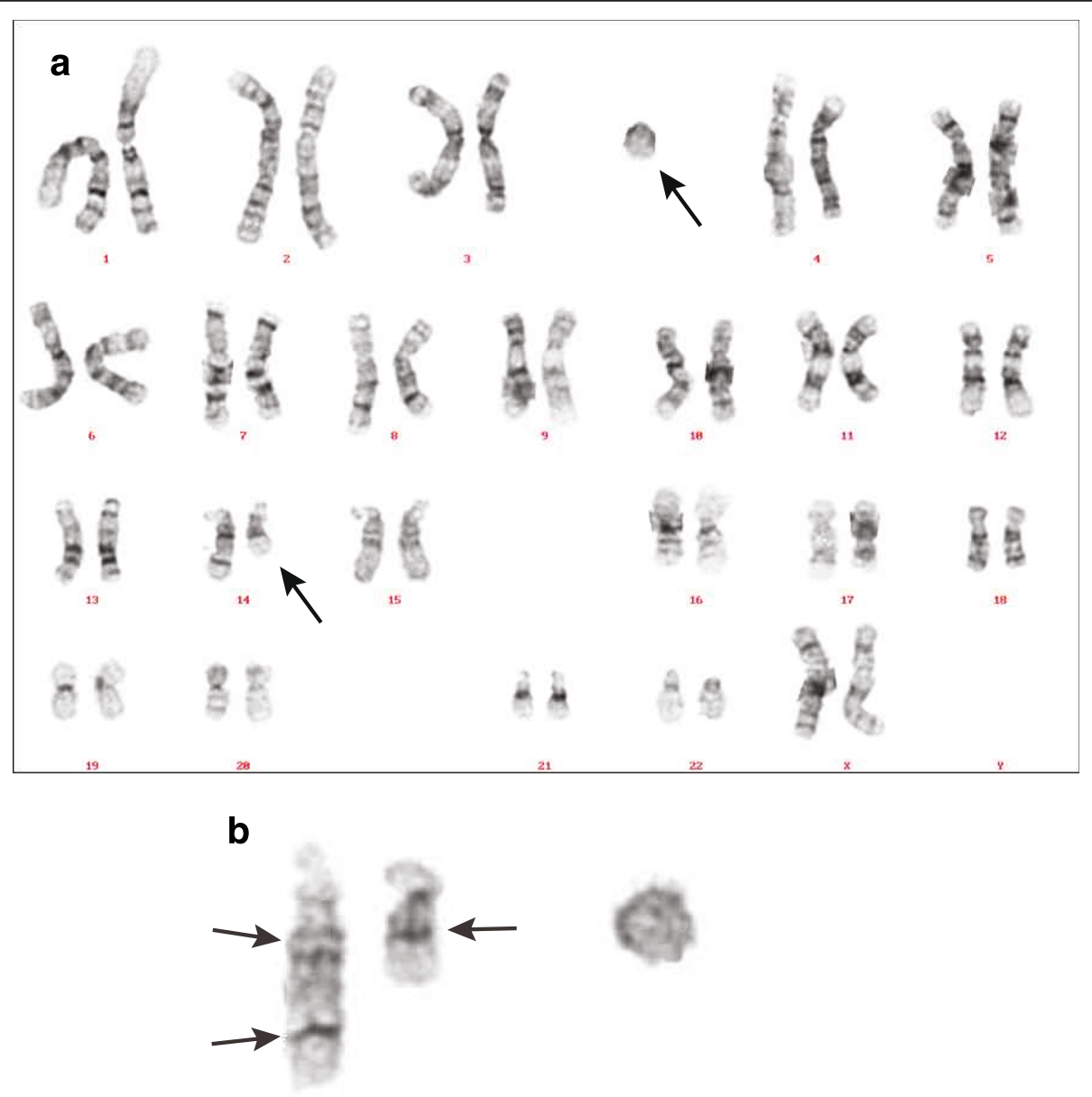

chr14 del(14)

$r(14)$

Figure 1 Chromosome analysis. a: Karyogram of the patient. b: Chromosome 14 and the r(14). Arrows on the left indicate the presumed position of the breakpoints. Arrow on the right side indicates the fusion of chromosome bands $14 q 12$ and 14q24.3. 
Human Genome Assembly hg19 (GRCh37), using BWA [17]. Using SVDetect to search for structural variations [18], we identified four read-pairs defining the breakpoints on the $\mathrm{r}(14)$ chromosome and the del(14) chromosome, with a resolution of appr. $1 \mathrm{~kb}$ at the $14 \mathrm{q} 12$ breakpoint, and $332 \mathrm{bp}$ at the 14q24.3 breakpoint (Figure 2c). The breakpoints were subsequently Sanger sequenced to identify their exact locations. Primers were designed with the use of the Primer3 software [19]. The PCR primer sequences were: D1: ttgatgcaaaaatcctcaataaaa (deleted derivative chromosome14, forward) and D3: gctttcatgagctggtgtgt (deleted derivative chromosome 14, reverse). Ring specific primers were: A1: taaaacagccaaaaattgattaaa $(r(14)$, forward) and A3: caagccatctcacattacacc $(\mathrm{r}(14)$, reverse)
(Figure 2a). An internal sequencing primer of the D1D3 fragment (D_internal) was: gaaggacctcttcaaggagaa (deleted derivative chromosome 14, forward). Using these primers (Figure 2a), we obtained PCR products from the patient's DNA but not from control DNA (Figure 2b). Sequences were read on an automated capillary sequencer (ABI 3130XL, Life Technologies) and analyzed with Chromas Pro version 1.5 (Technelysium Pty Ltd).

The position of the two breakpoints were 29.464.348 (hg19, proximal breakpoint) and 77.391.823 (hg19, distal breakpoint), with a 2 bp insertion (CC) at the proximal breakpoint, and a 5 bp (GGGGC) deletion at the distal breakpoint (Figure 2d).

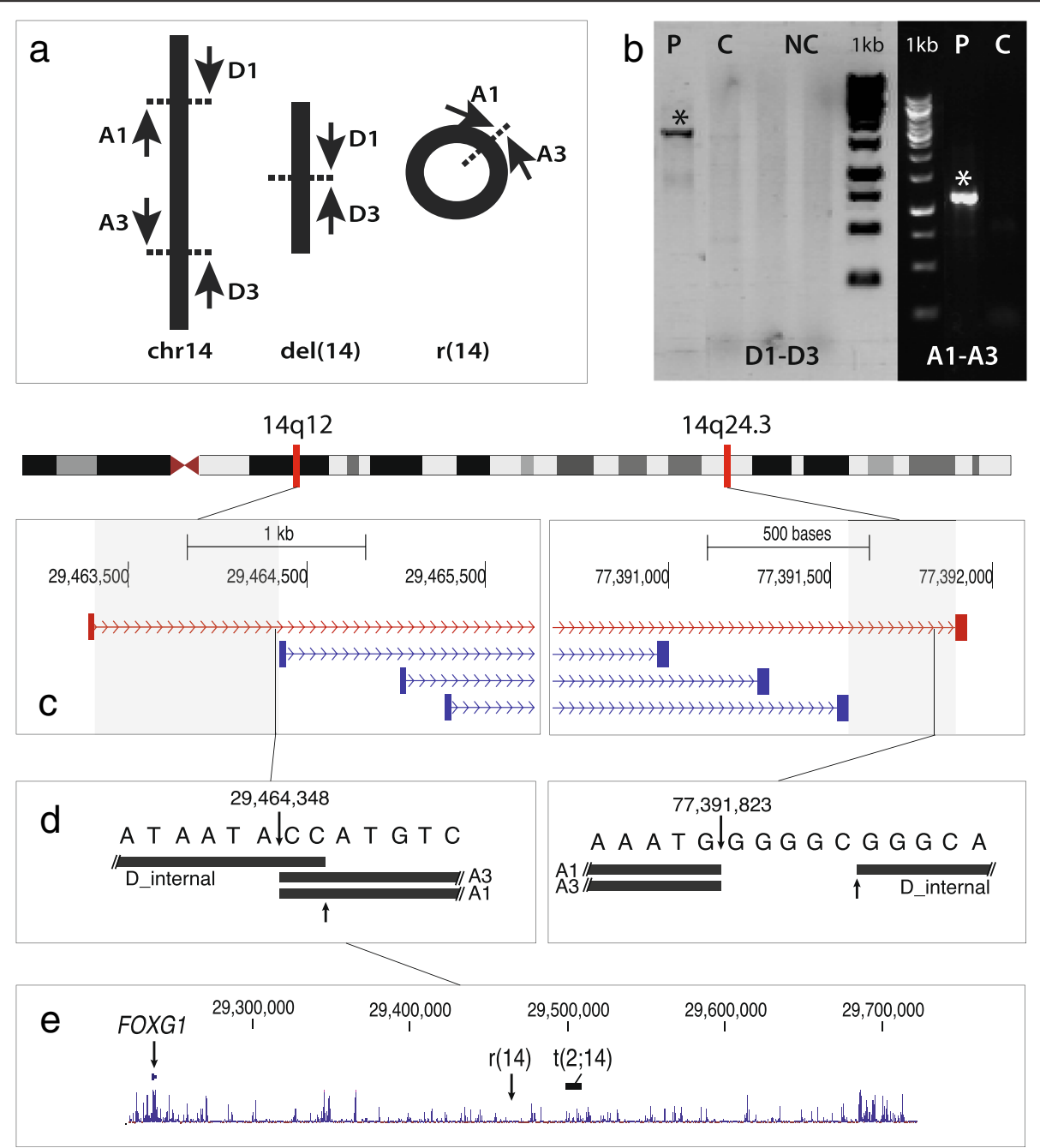

Figure 2 Molecular detection of the breakpoints. a: Schematic orientation of primers designed to amplify the breakpoints on the deleted and the ring chromosome 14. b: Agarose gel electrophoresis of PCR products obtained by primers D1-D3 and A1-A3. Specific amplifications $\left({ }^{*}\right)$ were observed at $62^{\circ} \mathrm{C}$ in patient (P) DNA but not in control (C) samples. NC: negative control. c: Mate-pair reads spanning the proximal and distal breakpoints, with resolutions corresponding to the shaded areas (proximal: 1,000 bp; distal: $\sim 330 \mathrm{bp}$ ). The thin grey lines indicate the position of the breakpoints as detected by Sanger sequencing. d: Position of BLAT sequences following Sanger sequencing, showing the location of the two breakpoints (upper arrows), the proximal two bp (CC) overlap and the distal 5 bp (GGGGC) deletion. e: Position of the proximal r(14) breakpoint in the highly conserved regulatory domain of FOXG1, proximal to the t(2;14)-breakpoint [13]. 
We did not detect any protein-coding genes in the breakpoint regions. However, both breakpoints disrupted predicted long non-coding RNA genes (lncRNA). The proximal breakpoint disrupted the IncRNA ENST00 000551227.1/RP11-148E17.1. The distal breakpoint interrupted the lncRNA TCONS 00022561. Importantly, the proximal breakpoint mapped $\sim 225 \mathrm{~Kb}$ downstream of FOXG1 (Figure 2e), a member of a transcription factor family critical for cortical development $[8,9,20]$.

\section{Fluorescence in Situ Hybridization (FISH)}

We validated the MPS results by Fluorescence In Situ Hybridization (FISH) performed according to standard protocols using $250 \mathrm{ng}$ biotin-14-dATP-labelled bacterial artificial chromosomes (BACs). We used the following BAC probes: RP11-24K5 (14q24.1), RP11-950C14 (14q24.3), RP11-35D12 (14q24.1) mapping to the predicted excised 14q24-region. The FISH analysis confirmed that the ring chromosome was composed of the excised region from $14 \mathrm{q}$ (Figure 3a). In order to exclude the possibility that a centromere on the ring chromosome contained centromeric chromosome 14 material, we performed FISH using $\alpha$-satellite DNA probes (Oncor, Gaithersburg, MD). As expected, alpha-satellite signals were observed on all chromosomes except on the ring (Figure $3 b$ ). Since the ring was detected in all cells suggesting that it was stable, we presume that $\alpha$ nonsatellite DNA containing neocentromere has been formed.

\section{Discussion}

We describe a severely affected female patient with a balanced chromosomal rearrangement consisting of an interstitial excision of chromosome 14q12q24 with subsequent ring formation. The proximal breakpoint at $14 \mathrm{q} 12$ disrupted a predicted lncRNA gene located in a gene desert approximately $225 \mathrm{~kb}$ downstream of FOXG1. Several patients with the FOXG1-syndrome have been reported with deletions or balanced rearrangements in the same downstream regulatory area of FOXG1 [e.g. 8,13]. Thus, the present breakpoint is located between FOXG1 and the $\mathrm{t}(2 ; 14)$ (q13;q13) breakpoint described in ref. 13 (Figure 2e), supporting the involvement of a long-range position effect, where distally located cis-regulatory elements are moved in trans with respect to the FOXG1-promoter [21]. The FOXG1-syndrome (former congenital variant of Rett syndrome) is a severe neurodevelopmental disorder classified by early onset of symptoms, including psychomotor delay, epilepsy and microcephaly [8-14]. These features were all present in our patient, along with many of the features of the $r(14)$-syndrome (Table 1). In contrast to the distinct facial features of the $r(14)$-syndrome, there was no report of dysmorphic features in our patient. This correlates with other reports of non-dysmorphic patients with the FOXG1-syndrome. Both the proximal and distal breakpoints disrupted predicted lncRNA genes. However, there is no known phenotype associated with either of these ncRNA genes, and the patient does not have any major

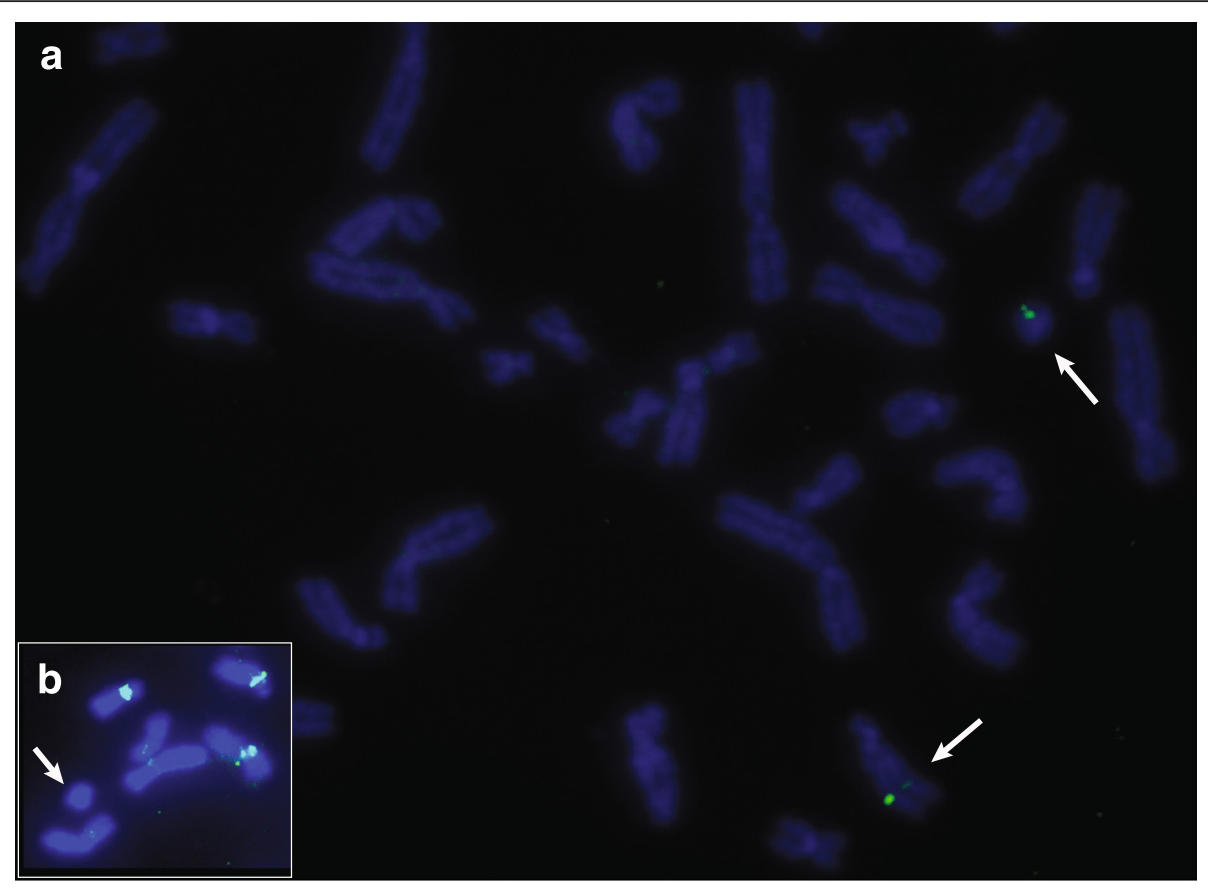

Figure 3 FISH analyses. a: The signals of BAC clone RP11-24K5 from the excised region are on the normal chromosome 14 and on the r(14). b: Absence of a-satellite DNA signal on the r(14). 
Table 1 Clinical features present in our patient, in the FOXG1-syndrome and in the $r(14)$-syndrome

\begin{tabular}{|c|c|c|c|}
\hline & This study & FOXG1-syndrome* & $r(14)$-syndrome $e^{* *}$ \\
\hline $\begin{array}{l}\text { Karyotype/molecular } \\
\text { characteristics }\end{array}$ & $47, X X$, del(14)(q12q24.3), + (r14) & FOXG1 point mutations, 14q12 CNV & Ring chromosome 14 \\
\hline Number of cases reported so far & Unique & $\sim 50$ & Less than 80 cases \\
\hline \multicolumn{4}{|l|}{ Clinical features } \\
\hline Pregnancy and neonatal period & Normal & Normal & Normal \\
\hline Postnatal growth deficiency & & Moderate & Mild to moderate \\
\hline Intellectual disability & Severe & Severe & Mild to severe \\
\hline Developmental delay & $\begin{array}{l}\text { Delayed psychomotor development } \\
\text { since } 2 \text { months of age }\end{array}$ & Severe & Severe \\
\hline Postnatal microcephaly & Yes & Postnatal microcephaly (-4/-6 SD) & Reported in the majority \\
\hline Speech-language development & No speech & Absent or minimal speech & Severely affected \\
\hline Social interaction & No eye-contact & $\begin{array}{l}\text { Poor eye contact, denoting a syndromic } \\
\text { form of autism }\end{array}$ & Autistic traits \\
\hline Walking & Unable & Unable & N/A \\
\hline Loss of psychomotor skills & & Hand skills, speech, communication skills & N/A \\
\hline Skeletal abnormalities & $\begin{array}{l}\text { Osteoporosis and thoraco-lumbal } \\
\text { scoliosis }\end{array}$ & Scoliosis, kyphosis & Scoliosis \\
\hline Facial dysmorphism & N/A & Only in patients with deletions & $\begin{array}{l}\text { Mild. Peculiar facial appearance only in patients with deletion } \\
\text { size greater than } 0.65 \mathrm{Mb} \text {, including blepharophimo-sis, } \\
\text { short bulbous nose, long philtrum, epicantal folds, small mouth }\end{array}$ \\
\hline Behaviour & N/A & $\begin{array}{l}\text { Poor sleep pattern, irritability (especially in infancy), } \\
\text { excessive crying/weeping, inappropriate laughing }\end{array}$ & Hyperactivity, aggressiveness \\
\hline Epilepsy & $\begin{array}{l}\text { Therapy-resistant epilepsy. Seizure type: } \\
\text { GTCS, often in series. Onset: } 1 \text { year-of-age. }\end{array}$ & $\begin{array}{l}\text { Infantile spasms in association with duplications, } \\
\text { CPS, GTCS, myoclonic seizures }\end{array}$ & $\begin{array}{l}\text { Early-onset (in most cases within the first year of life), } \\
\text { typically drug-resistant GTCS, CPS }\end{array}$ \\
\hline Ocular abnormalities & Loss of vision & Strabismus & $\begin{array}{l}\text { Retinal pigmentary anomalies, retinitis pigmentosa, } \\
\text { cataract, strabismus, maculopathy, glaucoma, myopia }\end{array}$ \\
\hline Motor and dyskinesias & Tetraplegia & $\begin{array}{l}\text { Hypotonia, spasticity, abnormal locomotion, stereotypic } \\
\text { movements (especially hand movements), dyskinesias } \\
\text { (chorea/athetosis/dystonia), bruxism, drooling } \\
\text { (sialorrhea), tongue protruding movements }\end{array}$ & Hypotonia, motoric stereotypies, hand flapping, echolalia \\
\hline $\begin{array}{l}\text { Gastrointestinal and } \\
\text { respiratory systems }\end{array}$ & N/A & $\begin{array}{l}\text { Feeding difficulties, aspiration, gastro-esophageal } \\
\text { reflux, constipation, breathing abnormalities }\end{array}$ & Susceptibility to infections of the respiratory tract \\
\hline Brain Imaging & $\begin{array}{l}\text { MRI (1994): central and cortical atrophy, } \\
\text { corpus callosum agenesis. Suspicion of } \\
\text { changes in cortical-spinal tracts }\end{array}$ & $\begin{array}{l}\text { Simplified gyral pattern, white matter hypoplasia } \\
\text { (frontal), hypogenesis of corpus callosum, } \\
\text { variable mild frontal pachygyria }\end{array}$ & $\begin{array}{l}\text { White matter hypoplasia, corpus callosum } \\
\text { abnormalities, hippocampal dysmorphisms, } \\
\text { cerebellar structural abnormalities }\end{array}$ \\
\hline
\end{tabular}

*FOXG1 data collected from $[10 ; 13 ; 14 ; 16] .{ }^{* *}$ r(14) data collected from $[2 ; 3 ; 6 ; 7 ; 15]$.

MRI (1994): central and cortical atrophy, Simplified gyral pattern, white matter hypoplasia variable mild frontal pachygyria 
clinical feature that has not been reported previously in the FOXG1- or $\mathrm{r}(14)$-syndromes. It has been suggested that genes within the $14 \mathrm{q} 11 \mathrm{q} 13$ region determine the visual impairment and epilepsy associated with the r(14)-syndrome, with FOXG1 being one of the candidate genes [7]. Indeed, the considerable phenotypic overlap between the present case, the FOXG1-syndrome and the r(14)-syndrome (Table 1) suggests that dysregulation of FOXG1 may be a significant factor behind the classical $r(14)$ syndrome.

\section{Conclusions}

We present a balanced rearrangement with an excision of 14q12q24, and an extra ring chromosome composed of the excised material. The severe clinical features are compatible with the FOXG1-syndrome, in line with the localization of the 14q12-breakpoint $225 \mathrm{~kb}$ downstream of FOXG1, within the regulatory domain where breakpoints are known to dysregulateFOXG1 by long range position effects. Moreover, the clinical overlap between our case, the FOXG1-syndrome and the classical r(14)syndrome, supports that dysregulation of FOXG1 may be an important factor involved in the clinical features of the classical $r(14)$-syndrome. Since classical $r(14)$ chromosomes would rarely have breakpoints within the FOXG1-regulatory domain, a likely mechanism for such a dysregulation may be the dynamic mosaicism associated with ring chromosomes, where sister chromatid exchanges within the ring lead to interlocked rings with subsequent breakage/reunion and/or aneuploidy mosaicism. Such a mechanism could also be relevant for the clinical features associated with other ring chromosomes, e.g. the development of tumors associated with the loss of specific tumor suppressors [22], and the epilepsy associated with loss of e.g. CHRNA4 and/or KCNQ2 in ring chromosome 20 mosaicism [23].

\section{Consent}

The study was approved by the Ethics Committee of Western Sealand (SJ-91), and written informed consent was obtained from the patient's parents.

\begin{abstract}
Abbreviations
r (14): Ring chromosome 14; FOXG1: Forkhead box G1; ID: Intellectual disability; CPS: Complex partial seizures; GTCS: Tonic-clonic seizures; SNP: Single nucleotide polymorphism; MPS: Mate-pair sequencing; IncRNA: Long non-coding RNA; BACs: Bacterial artificial chromosomes.
\end{abstract}

\section{Competing interests}

The authors declare that they have no competing interests.

\section{Authors' contributions}

$\mathrm{HH}$ and RSM acquired the clinical data and counseled the family. LK carried out microarray testing and karyotyping. MB performed mate-pair sequencing and helped DA with the analysis of the MPS-data. DA confirmed the breakpoints with Sanger sequencing and performed the FISH studies. NT and LK coordinated the study. DA, LK and NT edited the manuscript. All the authors read and approved the final manuscript.

\section{Acknowledgements}

We gratefully acknowledge the patient's family for participating in this study. This study has been supported by the Danish National Research Foundation and the Lundbeck Foundation.

\section{Author details}

${ }^{1}$ Department of Cellular and Molecular Medicine, Wilhelm Johannsen Centre for Functional Genome Research, University of Copenhagen, Copenhagen, Denmark. ${ }^{2}$ Danish Epilepsy Centre, Dianalund, Denmark. ${ }^{3}$ Institute of Regional Health Services Research, University of Southern Denmark, Odense, Denmark.

Received: 28 January 2015 Accepted: 19 March 2015

Published online: 09 April 2015

\section{References}

1. Morimoto M, Usuku T, Tanaka M, Otabe O, Nishimura A, Ochi M, et al. Case Reports Ring Chromosome 14 with Localization-related Epilepsy : Three Cases. Epilepsia. 2003;44:1245-9.

2. Ville D, De Bellescize J, Nguyen MA, Testard H, Gautier A, Perrier J, et al. Ring 14 chromosome presenting as early-onset isolated partial epilepsy. Dev Med Child Neurol. 2009;51:917-22.

3. Zollino M, Seminara L, Orteschi D, Gobbi G, Giovannini S, Della Giustina E, et al. The ring 14 syndrome: clinical and molecular definition. Am J Med Genet. 2009;149A:1116-24.

4. Giovannini S, Frattini D, Scarano A, Fusco C, Bertani G, Della Giustina E, et al. Partial epilepsy complicated by convulsive and nonconvulsive episodes of status epilepticus in a patient with ring chromosome 14. Epilept Disord. 2010;12:222-7.

5. Guilherme RS, de Freitas Ayres Meloni V, Sodrè CP, Christofolini DM, Pellegrino R, de Mello CB, et al. Cytogenetic and molecular evaluation and 20-years follow-up of a patient with ring chromosome 14. Am J Med Genet. 2010;152A:2865-9.

6. Youngs EL, Hellings JA, Butler MG. A clinical delineation and further delineation of the 14q32 deletion syndrome. Clin Dysmorphol. 2011;20:143-7.

7. Zollino M, Ponzi E, Gobbi G, Neri G. The ring 14 syndrome. Eur J Med Genet. 2012;55:374-80.

8. Schoichet SA, Kunde AS, Viertel P, Schell-Apacik C, von Voss H, Tommerup $\mathrm{N}$, et al. Haploinsufficiency of novel FOXG1B variants in a patient with severe mental retardation, brain malformation and microcephaly. Hum Genet. 2005; 117:536-44.

9. Ariani F, Hayek G, Rondinella D, Artuso R, Mencarelli MA, Spanhol-Rosseto A, et al. FOXG1 is Responsible for the Congenital Variant of Rett Syndrome. Am J Hum Genet. 2008;83:89-93.

10. Jacob FD, Ramanswamy V, Andersen J, Bolduc FV. Atypical Rett syndrome with selective FOXG1 deletion detected by comparative genomic hybridization: case report and review of literature. Eur J Hum Genet. 2009;17:1577-81.

11. Yeung A, Bruno D, Scheffer IE, Carranza D, Burgess T, Slater HR, et al. $4.45 \mathrm{Mb}$ microduplication in chromosome band 14q12 including FOXG1 in a girl with refractory epilepsy and intellectual impairment. Eur J Med Genet. 2009;52:440-2.

12. Brunetti-Pierri N, Paciorkowski AR, Ciccone R, Della Mina R, Bonaglia MC, Borgatti R, et al. Duplications of FOXG1 in 14q12 are associated with developmental epilepsy, mental retardation, and severe speech impairment. Eur J Hum Genet. 2011;19:102-7.

13. Kortüm F, Das S, Flindt M, Morris-Rosendhal DJ, Stefanova I, Goldstein A, et al. The core FOXG1 syndrome phenotype consists of postnatal microcephaly, severe mental retardation, absent language, dyskinesia, and corpus callosum hypogenesis. J Med Genet. 2011;48:396-406.

14. Allou L, Lambert L, Amsallem D, Bieth E, Edery P, Destrèe A, et al. 14q12 and severe Rett-like phenotypes: new clinical insights and physical mapping of FOXG1-regulatory elements. Eur J Hum Genet. 2012;20:1216-23.

15. Papa FT, Mencarelli MA, Caselli R, Katzaki E, Sampieri K, Meloni I, et al. A $3 \mathrm{Mb}$ Deletion in $14 \mathrm{q} 12$ causes severe mental retardation, mild facial dysmorphisms and Rett-like features. Am J Med Genet A. 2008;146:1994-8.

16. Guerrini R, Parrini E. Epilepsy in Rett syndrome, and CDKL5- and FOXG1gene-related encephalopathies. Epilepsia. 2012;53:2067-78.

17. Li H, Durbin R. Fast and accurate short read alignment with BurrowsWheeler transform. Bioinformatics (Oxoford, England). 2009;25:1754-60. 
18. Zeitouni B, Boeva $V$, Janoueix-Lerosey I, Loeillet $S$, Legoix-nè $P$, Nicolas $A$, et al. SVDetect: a tool to identify genomic structural variations from paired-end and mate-pair sequencing data. Bioinformatics. 2010;26:1895-6.

19. Untergasser A, Nijveen H, Rao X, Bisseling T, Geurts R, Leunissen JAM. Primer3Plus, an enhanced web interface to Primer3. Nucleic Acids Res. 2007;35:W71-4.

20. Hanashima C, Li SC, Shen L, Lai E, Fishell G. Foxg1 suppresses early cortical cell fate. Science. 2004;303:56-9.

21. Kleinjan DA, van Heyningen V. Long-range control of gene expression: emerging mechanisms and disruption in disease. Am J Hum Genet. 2005;76:8-32.

22. Tommerup N, Lothe R. Constitutional ring chromosomes and tumour suppressor genes. J Med Genet. 1992;29:879-82.

23. Giardino D, Vignoli A, Ballarati L, Recalcati MP, Russo S, Camporeale N, et al. Genetic investigations on 8 patients affected by ring 20 chromosome syndrome. BMC Med Genet. 2010;11:146.

\section{Submit your next manuscript to BioMed Central and take full advantage of:}

- Convenient online submission

- Thorough peer review

- No space constraints or color figure charges

- Immediate publication on acceptance

- Inclusion in PubMed, CAS, Scopus and Google Scholar

- Research which is freely available for redistribution 